SOI: $1.1 /$ TAS DOI: $10.15863 /$ TAS

International Scientific Journal Theoretical \& Applied Science

p-ISSN: 2308-4944 (print) e-ISSN: 2409-0085 (online)

Year: 2017 Issue: 11 Volume: 55

Published: $28.11 .2017 \quad \underline{\text { http://T-Science.org }}$
Tatyana Vladimirovna Cherkes

senior lecturer

Yanka Kupala State University of Grodno, Belarus

t_koteleva@mail.ru

Elena Viktorovna Flyantikova

senior lecturer

Grodno State Medical University, Grodno, Belarus alena-flint@mail.ru

SECTION 21. Pedagogy. Psychology. Innovations in the field of education.

\title{
REPRESENTATION OF THE KNOWLEDGE ABOUT UNIVERSAL VALUES IN RFL: THE USE OF MODERN EDUCATIONAL TECHNOLOGIES
}

\begin{abstract}
The article deals with the presentation of cultural material at the initial stage of teaching Russian as a foreignlanguage. The scientific recommendations for the development of an aesthetically advanced linguistic personality, tolerant and capable to dialogue of cultures, are presented and summarized in the theoretical part. The proposed types of practical assignments are based on lexico-grammatical and culturological material within the framework of the theme "Description of appearance" and are applicable to the A2-B2 training levels. The differentiated approach in the use of modern educational technologies helps to build communicative, linguistic and intercultural competence, which leads to the creation of new multicultural landmarks of axiological paradigm of human and world perception, to the formation and development of a linguistic personality open to intercultural communication.

Key words: Russian as a foreign language, universal values, dialogue of cultures, use of modern educational technologies.

Language: Russian

Citation: Cherkes TV, Flyantikova EV (2017) REPRESENTATION OF THE KNOWLEDGE ABOUT UNIVERSAL VALUES IN RFL: THE USE OF MODERN EDUCATIONAL TECHNOLOGIES. ISJ Theoretical \& Applied Science, 11 (55): 212-218.

Soi: http://s-o-i.org/1.1/TAS-11-55-27 Doi: crossef https://dx.doi.org/10.15863/TAS.2017.11.55.27

\section{РЕПРЕЗЕНТАЦИЯ ЗНАНИЙ ОБ ОБЩЕЧЕЛОВЕЧЕСКИХ ЦЕННОСТЯХ В РКИ: ИСПОЛЬЗОВАНИЕ СОВРЕМЕННЫХ ОБРАЗОВАТЕЛЬНЫХ ТЕХНОЛОГИЙ}

Аннотация: В статье рассматривается презентация культурологического материала на начальном этапе обучения русскому языку как иностранному. В теоретической части представлены и обобщены научные рекомендации для становления эстетически развитой языковой личности, толерантной и способной к диалогу культур. Предложенные типь заданий практической части основаны на лексикограмматическом и культурологическом материале в рамках темь "Описание внешности» и применимы для уровней обучения А2-В2. Дифференцированный подход в использовании современных образовательных технологий способствует формированию коммуникативной, языковой и межкультурной компетентности, что ведет к созданию новых, поликультурных ориентиров аксиологической парадигмы восприятия человека и мира, к становлению и развитию языковой личности, открытой к межкультурной коммуникации.

Ключевые слова: русский язык как иностранный, общечеловеческие иенности, диалог культур, использование современных образовательных технологий.

\section{Introduction}

Проблемой при обучении русскому языку как иностранному (далее РКИ) в рамках поликультурного образовательного пространства является то, что современная педагогическая модель предполагает не только формирование у иностранных студентов знаний о нормах и

правилах иного языка, но и включает в себя «обогащение образовательного процесса общечеловеческими ценностями, этническими ценностями, ценностями межкультурной коммуникации» [10]. Для этого преподавателю в процессе работы необходимо учитывать следующие факторы:
\end{abstract}


1) развивать познавательный интерес студентов к инокультурной общности, где действуют другие аксиологические парадигмы;

2) закладывать основы знаний и умений в области грамматического и лексического строя языка на материале лексики с национальнокультурной семантикой;

3) репрезентовать знания об общечеловеческих ценностях;

4) организовать субъект-субъектную творческую деятельность педагогов и учащихся» [10].

Особенно актуальна проблема презентации учебного материала, несущего в себе интеркультурный компонент, на начальном этапе обучения РКИ. К трудностям начального этапа обучения относят:

1) ограниченность лексического запаса инофонов, препятствующую восприятию информации;

2) сложности адаптационного периода в стране изучаемого языка;

3) затруднение в установлении контактов в интернациональной среде;

4) недопонимание, неприятие отличных от привычных в своей культуре особенностей поведения;

5) разницу в менталитете, а также в религиозных убеждениях и т.д.

\section{Materials and Methods}

В данной работе рассматривается процесс подачи культурологического материала на начальном этапе обучения с использованием современных образовательных технологий. Под понятием образовательная технология мы понимаем «модель и реальный процесс осуществления целостной педагогической деятельности, которая включает в себя индивидуально-групповую, информационнодиагностирующую, организационноразвивающую, деятельностно-эвристическую, духовно-гуманитарную и мотивационноуправленческую составляющие» [2]. Теоретическая часть посвящена представлению и обобщению существующих научных мнений, рекомендаций для развития эстетически развитой языковой личности, толерантной и способной к диалогу культур. В практической части на основе лингводидактической модели занятия РКИ, разработанной в рамках темы «Описание внешности человека», предъявляется дифференцированный подход к использованию современных образовательных технологий. Рассматриваемые типы заданий применимы для уровней обучения РКИ А2-В2: система упражнений направлена на поэтапное формирование коммуникативной, языковой и межкультурной компетентности, создание новых, поликультурных ориентиров аксиологической парадигмы восприятия человека и мира.

Известно, что перед преподавателем РКИ не ставится задача обращения представителя одной культуры в представителя другой, замены ценностных ориентиров и установок, необходимо осуществлять «знакомство инофона, сохраняющего свою принадлежность к определенной национальной культуре, с культурой страны изучаемого языка» [4, с. 87]. Результатом должна стать языковая личность, обладающая «культурно обусловленной ментальностью, картиной мира и системой ценностей [9, с. 107-108]» - утверждает О.А. Леонтович. По мнению автора, данная личность должна быть способной осознавать культурные различия, корректирующие аспекты коммуникативного поведения. Личность, для которой присуща модель поведения «Flex», одна из моделей поведения человека, оказавшегося в условиях иной культуры, выделенных К. Доддом. В данной модели отсутствует навязывание иной культуры, требование отказаться от собственной, а лишь предлагается сознание необходимости принятия нового культурного кода, осознание его [7]. Согласно мнению Додда, происходит формирование некой третьей культуры, представляющей синтез собственной $u$ инокультуры. Синтез и осознание моделей поведения, особенностей вербальных и невербальных средств, аксиологических ориентиров расширяет культурные и личностные стороны человека, способствуя познанию себя и окружающего мира, выводит нечто неявное, подсознательное на сознательный уровень и, таким образом, формирует человека третьей культуры.

Так, для формирования данной модели «Flex» необходима репрезентация знаний об образцах поведения, вербальных и невербальных средствах общения, знакомство с аксиологическими культурными ориентирами страны изучаемого языка. Анализ и сопоставление тех или иных реалий иной культуры с культурой собственной, становление и развитие уважительного к ним отношения способствуют формированию личностного роста иностранного обучающегося. Что в свою очередь, ведет к появлению новой, гармонично развитой личности, толерантно и благожелательно относящейся к мировому культурному наследию в целом.

Невозможно интуитивно понять и усвоить особенности новой культуры, потому что каждый человек представляет себя с позиций своей культуры, соотносит любые явления с теми критериями и стандартами, которые подсознательно заложены в его мировоззрении. Мы солидарны с позицией А. Вежбицкой, что «для описания специфических черт различных 
культур требуется универсальная перспектива и независимый от культуры аналитический подход. Теоретический каркас такого подхода могут составить универсальные человеческие понятия, то есть понятия, присущие каждому естественному языку» [12]. Для формирования межкультурной аксиологической парадигмы необходимо знакомство иностранцев с представлениями об общечеловеческих ценностях, к которым принадлежит «то действительно важное для людей, что непременно является надобным, желанным, что имеет непреходящую, существенную значимость практически для каждого нормального человека, независимо от его пола, расы, гражданства, социального положения и т. д. Общечеловеческие ценности высоко значимы для человечества как единства всех людей, также как и для всякого государства, поскольку оно отвечает или должно отвечать нуждам, интересам, потребностям общества и гражданина» [8]. В общечеловеческих ценностях выражаются потребности как отдельного человека, так и общества в целом. Так, одним из базовых аксиологических понятий является потребность человека в прекрасном. Однако представление о красоте может отличаться не только у представителей разных культур, но и у носителей одной и той же культуры. Помимо индивидуальных представлений о прекрасном, представителю каждой культуры присуще и определенное закрепленное общественное содержание, влияющее на восприятие. Как известно, целью преподавания РКИ является не нахождение различий в понятиях представителей различных культур, а донесение общечеловеческой эстетической ценности понятия красота, формирование у иностранных учащихся позитивного отношения к миру, к реалиям иной культуры, способности мировидения и мировосприятия сквозь призму прекрасного. Для успешной реализации данной цели необходимо комплексное использование различных технологий, которые «будут направлены на формирование субъектной позиции обучаемого в целостном образовательном процессе вуза, и строятся на механизме диалогичности, рефлективности и сотрудничества» [11].

Как известно, формирование представления о красоте как одной из эстетических общечеловеческих ценностей начинается на начальном этапе обучения, еще во время лингвистической работы на основе материала, касающегося социально-бытовой сферы общения иностранных учащихся (начиная с уровня A1-A2). Тема «Описание внешности человека» (словарная база и синтаксические конструкции) жизненно необходима для общения в стране изучаемого языка (как мы знаем, в преподавании РКИ приоритетен коммуникативный подход).
Знакомство с основными лексическими единицами, моделями предложений, используемыми для описания внешности, целесообразно проводить с использованием средств визуализации (презентаций, небольших видео, фотографий и т.д.), которые, как общеизвестно, улучшают эффективность восприятия незнакомого материала. Итак, студентам предлагается посмотреть презентацию, прочитать предложенный материал.

Упражнение 1. Прочитайте.

рост высокий / средний / низкий

Он (она) высокого (среднего / низкого) роста.

фигура стройная / спортивная, он худой / полный

У него (у нее) стройная (спортивная фигура). Он (она) худой (худая) / полньй (полная).

волосы длинные / короткие, тёмные / светлые / рыжие / седые, лысый, прямые / волнистые

У него (у нее) длинные темные прямые волосы. Он лысый.

глаза большие / маленькие, голубые / зелёные / карие / черные

У него (у нее) большие голубые глаза.

ресницы длинные / короткие

У него (унее) длинные ресницьы.

брови широкие / тонкие

У него (у нее) иирокие брови.

нос большой / маленький / курносый

У него (у нее) большой нос.

губы полные / тонкие

У него (у нее) полные губы.

красивая улыбка

У него (у нее) красивая ульбка.

борода, усы

У него есть борода / усы.

лицо доброе / злое

У него (у нее) доброе лицьо.

На данном этапе нами выбрана мультимедийная технология, так как она позволяет в рамках одного информационного потока использовать несколько типов информации (текст, видео, фото и т.д.), что способствует ее более эффективному восприятию, пониманию и запоминанию за счет того, что происходит воздействие на разные рецептивные каналы: зрительный, вербальный, слуховой.

Затем, после знакомства с новыми словами, ведется работа над закреплением лексического материала. На наш взгляд, при проведении данного вида работы целесообразным будет комплексное использование интерактивной игровой технологии и технологии обучения в сотрудничестве, так как применение данных технологий способствует взаимному обучению, умению слышать и слушать собеседника, учит гибкости и толерантности, а игровые моменты в условиях учебного процесса вызывают 
заинтересованность учащихся и помогают усвоению нового материала. Студентам предлагается описать человека, изображенного на слайде презентации / на фото/рисунке. Данный вид работы предлагается провести в командах.

Упражнение 2. «Больше! Лучше! Точнее!» Опишите данных людей.

Рефлексией данного задания можно сделать подведение итогов. Суммируемые в процессе описания балы подсчитываются, после чего выбирается команда-победитель. С помощью наводящих вопросов преподавателя: Почему победила эта команда? Что они рассказали о ...? Какие ошибки сделали вы? Какие слова вы забыли (вспомнили в прочессе соревнования?) Какие новые слова мы еше должны узнать, чтобы хорошо рассказывать о..? $и$ т.д. - еще раз повторяются новые лексико-грамматические конструкции.

Для закрепления введенного лексикограмматического материала предлагается провести следующий вид работы также в игровой форме, с применением интерактивных игровых технологий.

Упражнение 3. Отгадай, кто это.

а) Один из студентов выходит из аудитории. Он находится в позищии ведущего. В это время группа принимает решение, выбирая одного из студентов, которого по описанию внешности должен отгадать ушедший. После чего ведущий возвращается. Он задает вопросы, на которые остальные члены группь отвечают «да»или «нет»:

- У него карие глаза?

- Да

- Он высокого роста?

- Hem...

б) Учащимся предлагается нарисовать свой портрет. Затем преподаватель собирает рисунки и по очереди демонстрирует их всей группе. Задача учащиххя - узнать, кто изображен на портрете, а также объяснить, почему он так cчumaem:

- Я думаю, это Джон, потому что у него вьюшиеся черные волосы.

Данный вид работы используется для отработки лексико-грамматического материала, поскольку повышает мотивацию учащихся. Помимо игровой технологии, здесь также присутствуют элементы технологии проблемного обучения, так как в данных типах заданий существует проблемная ситуация (узнать, угадать), а также требуется самостоятельная активность учащихся (вопросы, ответы, версии), что благоприятствует не только творческому овладению данным лексико-грамматическим материалом, но и стимулирует развитие мыслительных способностей учащихся.
Для введения синтаксических моделей, используемых при описании внешности, учащимся предлагается прочитать диалоги. Предварительно преподаватель знакомит их с новыми конструкциями: Tbl очень изменился! Она очень изменилась! / Как он / она выглядит, а также с фразами удивления: Неужели! (Неужели ты женился!), Разве (Разве ты не сдал этот экзамен?), Я и не знал (Я и не знал, что тьл живешь в этом доме!), Что ты говоришь! (Что ты говоришь! Ты никогда не был в цчирке? Не может быть! (Ты уже дома? Не может быть!), Серьезно? (Ты не придешь? Серьезно?).

Упражнение 4. Прочитайте диалоги. Разыграйте их. Составьте подобные.

а) - Привет, Антон! Я видел тебя в кафе. Tbl был с девушкой. Кто это?

- Ты не узнал? Это моя младшая сестра!

- Не может быть! Ты, наверное, иутишь! Она очень изменилась. Она была маленькая, у нее были короткие светлье волосы.

- Ну да, все правильно, но это было 5 лет назад. Сейчас она высокая, у нее длинные светлье волосы и красивая фигура.

- Да, она красавица!

б) - Сергей, $к$ тебе приходил какой-то молодой человек.

- Как он выглядит? Высокий? У него большие карие глаза и короткие тёмные волосы?

- Нет, он невысокого роста. И у него рыжие волосы. Он очень симпатичный.

- О, это, наверное, Олег. Неужели он приехал!

Данный вид работы направлен на формирование коммуникативной компетентности: психологической и языковой готовности к общению на иностранном языке, снятию определенного психологического барьера. То есть в данном случае была применена технология коммуникативного обучения, направленная на осмысление, оценку и предъявление языкового материала.

Далее студентам предлагается работа с фотографиями. Предварительно преподаватель готовит презентацию, в которой используются детские фото членов группы (можно взять для большей заинтересованности и фотографию самого преподавателя). Студентам предлагается узнать, кто изображен на снимках, и сравнить с тем, как данный человек выглядит сейчас. При этом используются фразы Он (она) очень изменился (изменилась) / Он (она) совсем не изменился (не изменилась). Раньше у него (у нее) были короткие волосы, а сейчас ... .

Выполнение данного задания проводится в виде дискуссии: Поспорьте! Аргументируйте свою точку зрения! Почему Bы (не) согласны? преподавателю в процессе дискурса отведена организующее-направляющая роль. Данный вид 
работы соответствует применению технологии развития критического мышления, где учащимися актуализируются и обобщаются имеющиеся знания по теме, проводится их определенный отбор для решения той или иной учебной задачи.

Для формирования навыка оперирования введенным лексико-грамматическим материалом студентам предлагается познакомиться с текстомописанием внешности друга.

Упражнение 5. Прочитайте текст. Расскажите о своем друге.

\section{Мой друг}

У меня есть друг. Его зовут Иван. Он приехал из России. Ему 22 года. Иван высокого роста. У него красивая спортивная фигура, потому что он занимается спортом. $У$ него короткие прямые светлье волосы, большие зеленые глаза, светлье короткие реснищьы, широкие брови, небольшой нос, полные губы $и$ красивая ульбка. Иван добрый и весельй. Он любит помогать друзьям. У него хорошее чувство юмора, он любит шутки. Он честный $u$ открытый человек. Он очень общчительный, поэтому у него много друзей. Иван очень энергичный человек. У него много хобби. Он любит спорт, он любит гулять $u$ путешествовать. Друзья говорят, что у него золотой характер.

Преобразование данного текста с целью описания собственного, реально существующего друга направлено на приобретение иностранными учащимися личностного опыта иноязычного общения. В данном случае нами был использована технология коммуникативного обучения, благодаря которой учащимися используется репрезентативная функция языка, то есть язык выступает средством для решения задачи (передаче информации о друге).

Упражнение 6. «Моя мама - самая красивая!»: составьте текст-описание внешности и характера мамы, подготовьте презентацию.

В процессе работы над заданиями подобного типа, помимо непосредственных учебных задач (приобретения знаний, умений и навыков для овладения языком как средством общения), решается задача формирования ценностного отношения личности к красоте в различных ее проявлениях. Несомненно, мама - самое прекрасное для всех людей. И красота матери реализуется, с одной стороны, на примере конкретного человека, с другой стороны, существует во взаимодействии любого человека с миром. Именно эта общность, это сходство позволяет увидеть и положительно оценить разную красоту, понять, что прекрасное - это не сочетание форм и цветов, а особое, личностное отношение к предмету или явлению.
Проектная технология, определяющая выполнение данного задания, способствует интеграции имеющихся знаний и умений, необходимых для решения поставленной задачи, формированию чувства сопричастности к изучаемому материалу, личностный вклад, что в конечном итоге приводит к формированию ценностно-смысловой устремленности личности. Так как выполнение данного задания предполагает не только говорение, но и слушание, умение поддержать диалог, то оно положительно влияет и на формирование культуры общения, способствует расширению кругозора.

Увидеть и понять красоту в различных ее проявлениях позволяет работа с картинами. Вниманию иностранных студентов предлагаются работы русских художников. Для создания словесного портрета и последующего дискурса мы обратимся к творчеству современного русского художника И.С. Глазунова. С использованием мультимедийной технологии и технологии обучения в сотрудничестве мы сделаем небольшую виртуальную экскурсию по официальному сайту И. Глазунова [3], предоставив учащимся время на поиск и изложение информации об интересных фактах биографии художника. Для этого группа делится на подгруппы, после чего каждая подгруппа работает над «своей» частью задания: «Детство художника», «Молодые годы», «Пусть к успеху», «Личная жизнь» и т.д. Далее части биографии с комментариями вписываются в сводную электронную таблицу на интерактивной доске, а также в тетради учащихся. После чего группа «посещает» картинную галерею. В цикле произведений искусства, посвященных женщинам, у художника есть работы, на которых изображена его дочь. Среди них - портреты девушки в современной, а также традиционной русской одежде. Для обсуждения художественного произведения группа делится на команды, и для дискурса предлагаются одни и те же вопросы. А потом сравниваются полученные результаты.

Упражнение 6. Рассмотрите картину. Опишите изображенного на ней человека. Как вы думаете, что понравилось художнику в этом человеке? Как вы думаете, какой характер у этого человека? В чем его красота?...

Данный вид работы способствует коммуникативному и когнитивному развитию учащихся посредством овладения способами формулирования мысли, развивает способность речепорождения, а также стимулирует развитие эмоционально-чувственной сферы. Формируется представление о том, что каждое мнение ценно, а красота многолика и имеет право быть разной. Для закрепления данного эмоциональночувственного опыта учащимся предлагается описать картину, выполненную в портретном 


\begin{tabular}{|c|c|c|c|c|c|c|}
\hline Impact Factor: & $\begin{array}{l}\text { ISRA (India) } \\
\text { ISI (Dubai, UAF } \\
\text { GIF (Australia) } \\
\text { JIF }\end{array}$ & $\begin{array}{l}=1.344 \\
=0.829 \\
=0.564 \\
=1.500\end{array}$ & $\begin{array}{l}\text { SIS (USA) } \\
\text { PИНЦ (Russia) } \\
\text { ESJI (KZ) } \\
\text { SJIF (Morocco) }\end{array}$ & $\begin{array}{l}=0.912 \\
=\mathbf{0 . 2 0 7} \\
=\mathbf{3 . 8 6 0} \\
=\mathbf{2 . 0 3 1}\end{array}$ & $\begin{array}{l}\text { ICV (Poland) } \\
\text { PIF (India) } \\
\text { IBI (India) }\end{array}$ & $\begin{array}{l}=6.630 \\
=1.940 \\
=4.260\end{array}$ \\
\hline
\end{tabular}

жанре, одного из своих национальных художников, объяснить присутствующим, что прекрасного увидел в этом лице художник. В процессе работы над данными видами заданий используются в комплексе как проектные технологии, так и технологии коммуникативного и проблемного обучения. Итогом выполнения заданий станет рефлексия, в результате которой можно будет сделать вывод, что искусство порождается в обществе, неся в себе ценности той или иной культуры. И способность понять культуру общества позволяет понять цели общества, которые, по мнению С.И. Гессена, определяются его культурой [1].

Общечеловеческое понимание красоты не отрицает еe индивидуального представления. Работа с пословицами и поговорками еще раз обращает на это внимание учащихся.

Упражнение 7. Прочитайте пословицу. Скажите, как вы понимаете ее значение. Аргументируйте свою точку зрения. Предложите ваши национальные пословицы и поговорки о красоте.

Кому что идет, то и красиво.

Красота - от глаз и уст.

Красота сердияа дороже красоты лиияа [5].

Работу над понятием внешней и внутренней красоты можно продолжить, взяв за основу стихотворение Н.А. Заблоцкого «Некрасивая девочка».

Упражнение 7. Прочитайте стихотворение. Ответьте, на вопрос автора: «..что есть красота

И почему ее обожествляют люди?

Сосуд она, в котором пустота,
Или огонь, мерцающий в сосуде?» [6].

Скажите, что понимал автор под огнем, меризающим в сосуде. Предложите, чем можно наполнить данный сосуд, чтобы человек считался прекрасным. Опишите идеального человека.

\section{Conclusion}

Работа над предложенными видами заданий ведется с применением технологии развития критического мышления, для которого характерно высказывание собственного мнения, оценочность, открытость новому. В процессе выполнения данных заданий происходит переработка полученных знаний, норм, сопоставление их с уже имеющимися на базе личного опыта. Вследствие чего происходит выработка некоего нового знания, развитие мыслительных способностей, рефлексия, приобретение навыков самостоятельной поисковой деятельности, развитие творческих способностей.

Итак, с помощью современных технологий реализуется одна из основных целей обучения РКИ - посредством развития языковой, коммуникативной и социокультурной компетентности способствовать поликультурному диалогу, служить средством презентации культурных, эстетических ценностей разных стран. Формирование у иностранных учащихся представления о красоте как общечеловеческой ценности, осознание того, что прекрасное существует в своих разнообразных проявлениях во многих аспектах жизни приводит к становлению иностранного студента как медиатора культур.

\section{References:}

1. Gessen S. I. (2013) Osnovyi pedagogiki. Vvedenie v prikladnuyu filosofiyu // Available: http://www.twirpx.com/file/779791/ (Accessed: 13.09.2017)

2. Gorovaya V.I. Petrova N.F. (2008) Obrazovatelnyie tehnologii i tehnologicheskaya kultura sovremennogo pedagoga // Available: www.toptechnologies.ru/ru/article/view?id=24253 (Accessed: 25.11.2017)

3. Glazunov Ilya (2002-2017) // Available: http://glazunov.ru/ (Accessed: 20.11.2017)

4. Gudkov D. B. (2003) Teoriya i praktika mezhkulturnoy kommunikatsii. - Moscow: Gnozis, 288
5. Dal V.I. Poslovitsyi russkogo naroda // Available: http://hobbitaniya.ru/dal/dal.php // (Accessed: 13.10.2017)

6. Zabolotskiy, N.A. (1955) Nekrasivaya devochka // Available: http://www.worldart.ru/lyric/lyric.php?id=13244 // (Accessed: 02.11.2017)

7. Dodd Carley Dynamic of intercultural communication // Available: http://trove.nla.gov.au/work/7354350

(Accessed: 10. 03. 2017)

8. Efimov V., Talanov V. Obschechelovecheskie tsennosti // Available: http://razumru.ru/humanism/journal/49/yef_tal. htm (Accessed: 08.10.2017) 


\begin{tabular}{l|lrl|l|ll} 
& ISRA (India) & $=\mathbf{1 . 3 4 4}$ & SIS (USA) & $=\mathbf{0 . 9 1 2}$ & ICV (Poland) & $=\mathbf{6 . 6 3 0}$ \\
Impact Factor: & ISI (Dubai, UAE) $=\mathbf{0 . 8 2 9}$ & PUHL (Russia) $=\mathbf{0 . 2 0 7}$ & PIF (India) & $=\mathbf{1 . 9 4 0}$ \\
& GIF (Australia) & $\mathbf{0 . 5 6 4}$ & ESJI (KZ) & $=3.860$ & IBI (India) & $=\mathbf{4 . 2 6 0}$ \\
& JIF & $\mathbf{1 . 5 0 0}$ & SJIF (Morocco) & $=\mathbf{2 . 0 3 1}$ & & \\
\hline
\end{tabular}

9. Leontovich O. A. (2003) Rossiya i USA: Vvedenie $\mathrm{v}$ mezhkulturnuyu kommunikatsiyu. - Volgograd: Peremena, 399

10. Safonova I. A. (2014) Mezhkulturnaya kommunikatsiya v aksiologicheskom aspekte // Available:

http://www.uchebilka.ru/kultura/97906/index.ht ml (Accessed: 08.10.2017)
11. Shamonina, G. Sovremennyie pedagogicheskie tehnologii v obuchenii russkomu yazyiku kak inostrannomu // Available: http://masterrki.net/docs/Shamonina012013.pdf (Accessed: 20.11.2017)

12. Vezhbitskaya A. (2014) Semantika, kultura i poznanie // Available: http://philology.ru/linguistics1/wierzbicka93.htm (Accessed: 22.09.2017) 